\title{
Flow and Heat Transfer Analysis of an Inlet Guide Vane with Closed-loop Steam Cooling
}

\author{
Siping Zhai ${ }^{1}$, Chao Zhang ${ }^{1^{*}}$, Baitao $\mathrm{An}^{2}$, Xiaoliang $\mathrm{Mao}^{3}$ \\ ${ }^{1}$ School of Automation, Tianjin University of Technology, Tianjin, 300384, China \\ ${ }^{2}$ Institute of Engineering Thermophysics, Chinese Academy of Science, Beijing, 100190, China \\ ${ }^{3}$ Datang Weihe Thermal Power Plant, Xianyang, 710004, China \\ Corresponding author E-mail:czhangxj@163.com
}

Keywords: Conjugate heat transfer; Closed-loop Steam cooling; Overall cooling efficiency; Numerical simulation.

\begin{abstract}
This paper aims to numerically investigate the overall cooling efficiency of a closed-loop steam cooling scheme with 3 separated cooling circuits designed for an inlet guide vane. Conjugate heat transfer simulation is carried out with the Shear Stress Transport (SST) turbulence model. The result indicates that most regions of vane surface are well cooled, but some of trailing edge region and the turning corner parts at mid-chord region suffer high temperature. The flow and heat transfer in each cooling circuit are analyzed in detail, and the key problem of the current cooling scheme design is found.
\end{abstract}

\section{Introduction}

Thermal efficiency and specific power output of gas turbine increase with increasing turbine inlet temperature [1]. Nowadays, turbine inlet temperature is far beyond the allowable temperature of metal blades, thus efficient cooling technology is essential to keep an acceptable temperature of turbine blades for life and safety requirements.

There are two kinds of cooling design method in terms of coolant difference, namely, open-loop air cooling and closed-loop steam cooling. As the conventional open-loop air cooling, cool air extracted from compressor flow into the turbine vanes and blades, and then mixes with the main flow hot gas. The extraction of the compressed air imposes a penalty to the thermal efficiency. The reduction of the gas turbine performance due to the increased coolants may overtake the benefits from the increase of turbine inlet temperature. Closed-loop steam cooling is an alternative cooling technology, which the coolant doesn't mix with the main flow hot gas [2]. Because of the higher heat transfer performance of steam, only internal cooling or a few more film cooling may be sufficient to complete the cooling task. As a novel and promising technology, closed-loop steam cooling attracted many researchers' and gas turbine manufacture's attention [3-6]. The complexity of internal cooling configurations was different due to the steam coolant pressure and the level of turbine inlet temperature. Through the previous studies, in spite of different cooling structures employed, the cooling schemes in the leading edge portion and the mid-chord section worked well. But the trailing edge portion was by far not satisfactorily cooled using only enhanced internal convention cooling, and open-loop air cooling was designed in reference [4]. A novel internal cooling structure named impingement-tabulated baffles cooling structure was proposed by Hu [7] to solve this problem.

Conjugate heat transfer simulation has been applied more and more to predict the flow and temperature field of turbine vanes and blades. Compared with conventional temperature prediction method, the numerical simulations in [8] showed the superiority, especially in the complex geometry and flow structure region.

In the present paper, conjugate heat transfer simulation is carried out based on the closed-loop steam cooling design by Hu [7]. The overall cooling efficiency is evaluated, and the flow and heat transfer are analyzed in detail for all cooling circuits. 


\section{Geometry and computational setup}

A general view of the whole computation domain and the inlet guide vane with closed-loop cooling structures are shown in Fig. 1. There are 3 separate cooling circuits named circuit 1 to circuit 3 are designed in leading edge portion, mid-chord portion and tailing edge portion respectively. The downward hollow arrows indicate the coolant inflow loop, otherwise the coolant recovery loop.

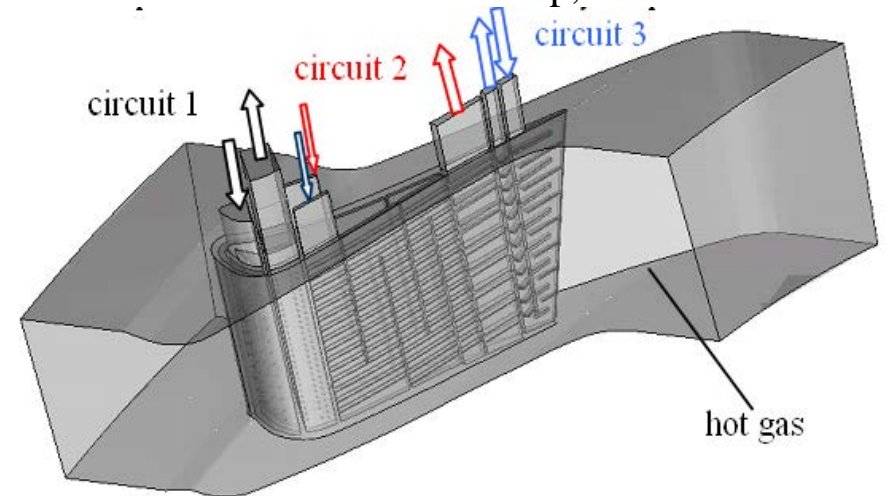

Fig.1 Sketch of the inlet guide vane and cooling circuits

The geometry details of cooling structures are shown in Fig.2 Fig.4. In the leading edge portion, the most effective jet impingement is arranged for highest thermal load. Fig. 2 shows the impingement holes distribution. In the coolant inflow loop, there are totally 5 rows of impingement holes in the coolant inflow loop, labeled with row 1 to row 5 . At the pressure side, there is no impingement hole. Row 1 is exactly located at the stagnation line, and row 2 to row 5 is located at the suction side. In the coolant recovery loop, there are 3 rows of tapered impingement holes on the suction side and the pressure side, respectively. Fig. 3 shows the cooling structures in the cooling circuit 2 . There are 2 coolant inflow loops at the pressure side and suction side respectively, and these two flows converge and outflow through one ribbed recovery loop. Smooth serpentine passages are arranged at the pressure side, and augmented serpentine passages with rib tabulators are arranged at the suction side. Fig. 4 shows the overview cooling structures in cooling circuit 3 . In the coolant inflow loop, a novel cooling configuration named impingement-tabulated baffles structure is arranged. The coolant flow accelerates along the reduction of cross-section areas, and the impingement effects occur at the trailing edge. In the coolant recovery loop, $60^{\circ}$ inclined V-shaped ribs are arranged.

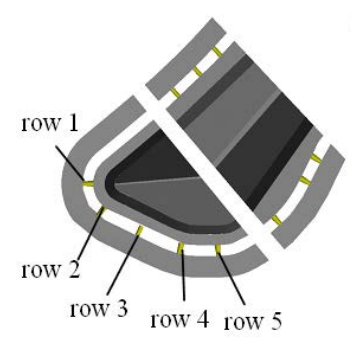

Fig. 2 Cooling Structures in circuit 1
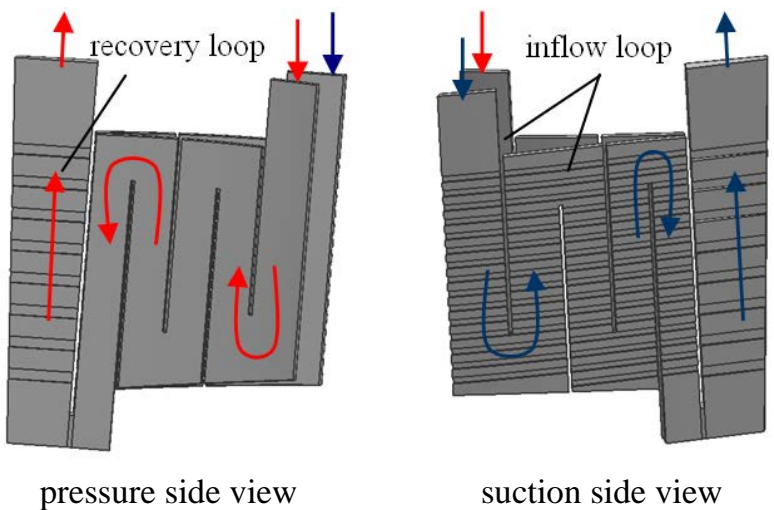

suction side view

Fig. 3 Cooling Structures in circuit 2

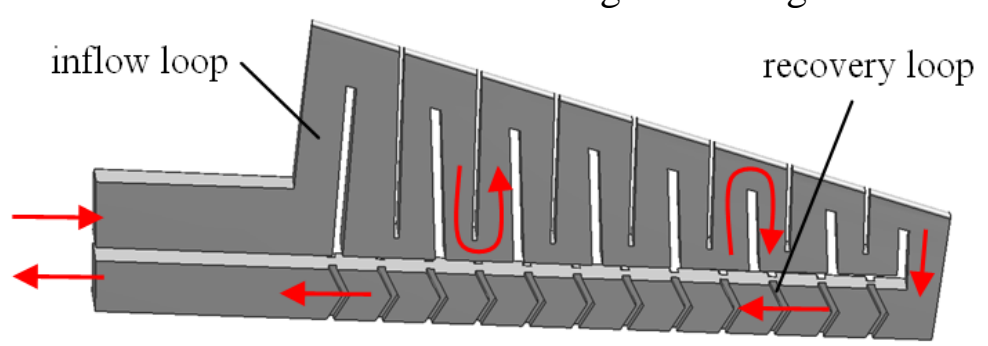

Fig. 4 Cooling Structures in circuit 3 
The conjugate heat transfer computation is performed by using the commercial software package ANSYS CFX. The three dimensional compressible Navier-Stokes equations are solved in the hot gas and coolant domains and the three dimensional Fourier equations are solved in the metal vane domain. The two-equation shear-stress turbulence model SST is selected in the present simulation because of good performance and comparatively low computational costs. The SST model was verified by previous researches $[9,10]$ for the accurate prediction of heat transfer.

Fig. 5 shows overview of the unstructured computation meshes. In order to avoid additional data transfer error, nodes of meshes on fluid-solid interfaces are 1:1 connection. The total number of whole computational meshes is about 18.30 millions. There are 15 prism layers in the hot gas domain, and 8 prism layers in the steam domains. The first boundary layer height near the wall is $0.001 \mathrm{~mm}$, and the corresponding $\mathrm{y}^{+}$is about 2.5 .

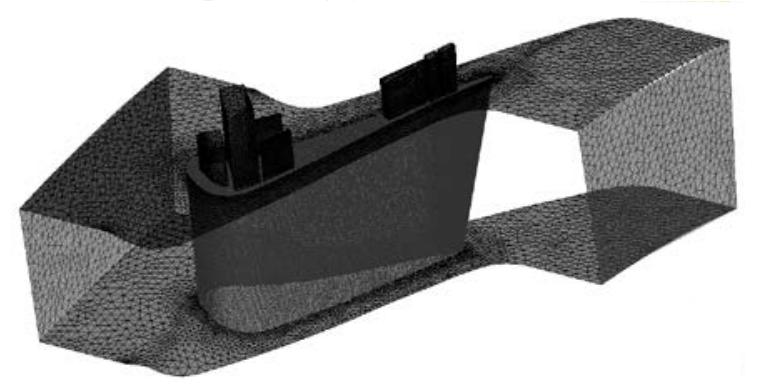

a) mesh distribution of the computation domain

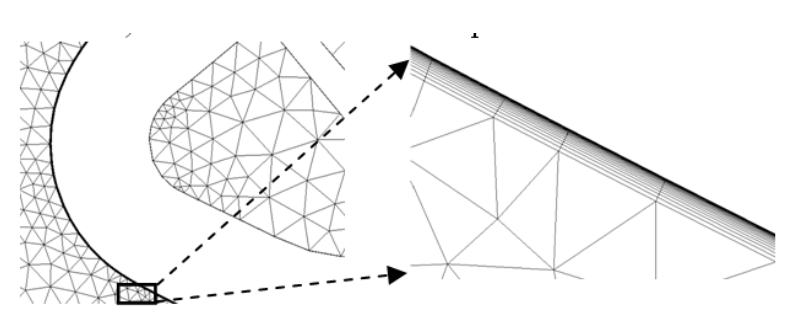

b) prism layers of the hot gas domain

Fig. 5 Unstructured computation meshes

The boundary conditions of hot gas flow domain are defined the same as in [11]. As the steam cooling circuits, the inlet total pressure of all circuits is set to $1.8 \mathrm{MPa}$ with the turbulence intensity of $10 \%$, and the total temperature is $700 \mathrm{~K}$. The average static pressure of outlet is $1.1 \mathrm{MPa}$. The hub and shroud surfaces are set to be adiabatic. The convergence level is below $10^{-4}$ for the RMS residuals, and the mass flow imbalance is below $1 \%$.

\section{Overall cooling efficiency distribution}

In order to access the steam cooling performance, the overall cooling effectiveness (OCE) is defined as follows:

$$
\mathrm{OCE}=\left(T_{\mathrm{g}, \mathrm{t}}-T_{\mathrm{e}, \mathrm{m}}\right) /\left(T_{\mathrm{g}, \mathrm{t}}-T_{\mathrm{c}, \mathrm{t}}\right)
$$

Where $T_{\mathrm{g}, \mathrm{t}}$ is the inlet total temperature of the hot gas domain, $T_{\mathrm{e}, \mathrm{m}}$ is the vane external surface metal temperature, and $T_{\mathrm{c}, \mathrm{t}}$ is the inlet total temperature of the coolant domains. Suppose the maximum allowable temperature of current vane is $1173 \mathrm{~K}$, then the minimum allowable overall cooling effectiveness is 0.396 .

Fig. 6 shows the external surface OCE contours on the pressure side and suction side. Most of the external surface is well cooled, including the leading edge, most of the mid chord portion, and some of the trailing edge portion, and the area-averaged OCE of the whole external surface is 0.487 . But three low OCE regions (marked as A, B and C) exist on the trailing edge portion and one low OCE region (marked as $\mathrm{D}$ ) exists on the mid-chord of the suction side near-hub region. The minimal OCE of 0.278 is located in the region A.

Table 1 shows the coolant to hot gas mass flow rate ratio and the area-averaged temperature at outlet in all three circuits. The ratio of total coolant mass flow rate to passage air mass flow rate is $1.206 \%$. The coolant mass flow in circuit 3 is relatively small to the mass flow in circuit 1 and circuit 2. Due to the less coolant in circuit 3, the area-averaged temperature at the outlet of circuit 3 is $1141.70 \mathrm{~K}$, which is just slightly lower than the maximum allowable metal temperature. The averaged temperatures at the outlet in circuit 1 and 2 are relatively lower than that in circuit 3 . 

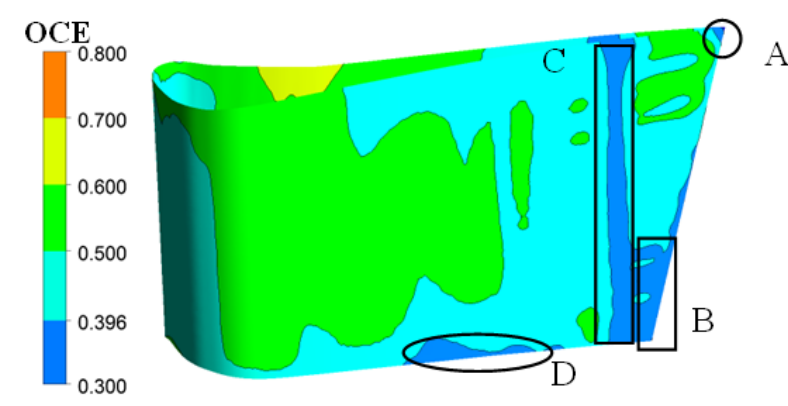

suction side view

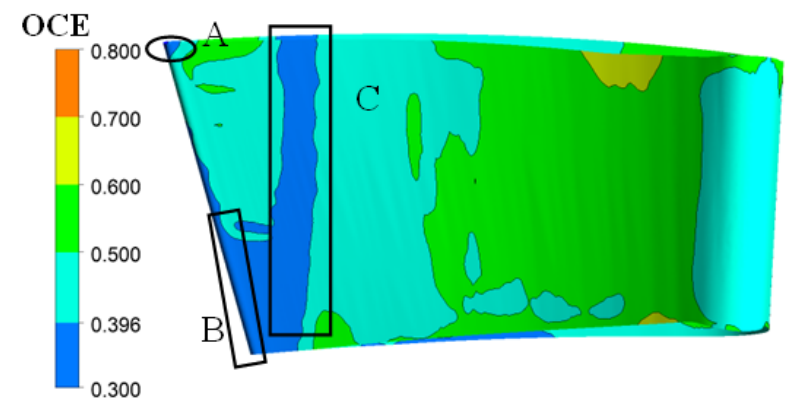

pressure side view

Fig. 6 External surface overall cooling effectiveness contours Table 1 Coolant consumption details of all cooling circuit

\begin{tabular}{c|c|c}
\hline Circuit No. & $\begin{array}{c}\text { Coolant to hot gas mass flow } \\
\text { rate ratio (\%) }\end{array}$ & $\begin{array}{c}\text { Area-averaged temperature at } \\
\text { circuit outlet (K) }\end{array}$ \\
\hline 1 & 0.671 & 791.08 \\
\hline 2 & 0.483 & 933.65 \\
\hline 3 & 0.052 & 1141.70 \\
\hline total & 1.206 & \\
\hline
\end{tabular}

\section{Flow and heat transfer analysis}

The heat transfer coefficient (HTC) $h_{\mathrm{i}}$ at the vane inner surface is defined:

$$
h_{i}=q /\left(T_{i, m}-T_{c, t}\right)
$$

Where $q$ is the heat flux rate, $T_{\mathrm{i}, \mathrm{m}}$ is the vane internal surface metal temperature.

Fig. 7 shows the coolant flow in circuit 1 and OCE distribution at the impingement target wall. The flow accelerates caused by the decrease of flow area after the metal insert, and then the coolant flows through the tapered impingement holes and accelerates again to impinge the wall. The coolant in the recovery loop flows through the impingement holes to cool the pressure side and suction side. The impingement effect is obvious on both suction side and leading edge region. Even no impingement hole is arranged at the beginning of the pressure side, the cooling effect is still satisfactory because of the relatively low heat loading. Fig. 8 shows the coolant flow and heat transfer distribution in circuit 2 on the suction side. $90^{\circ}$ horizontal ribs arranged at the turning corner 3 are supposed to enhance the heat transfer performance, but flow separation exists here. This flow separation finally results in low velocity and poor heat transfer performance, and low OCE region D occur at the turning corner 3 portion (see Fig. 6). The smooth serpentine passage is sufficient here, due to the relatively low heat loading at the pressure side.

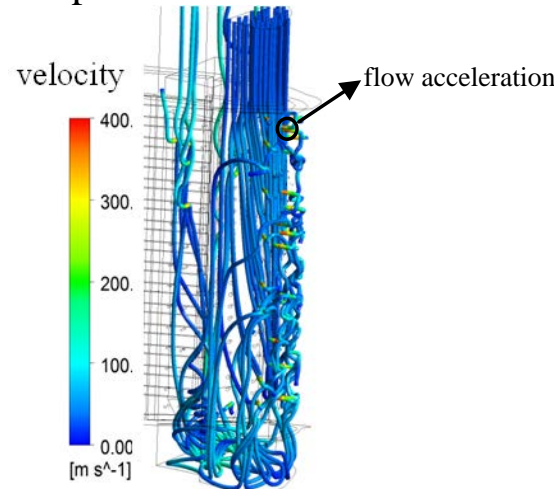

a) coolant flow
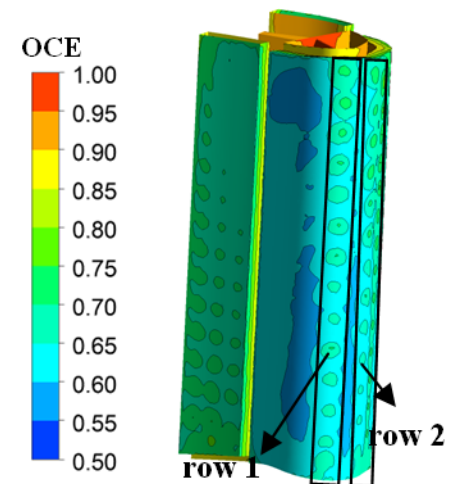

b) OCE contours at the target wall of impingement

Fig. 7 The coolant flow and heat transfer in circuit 1 


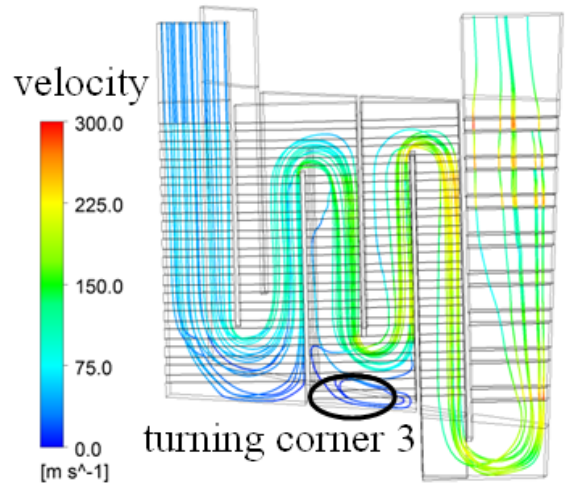

a) coolant flow
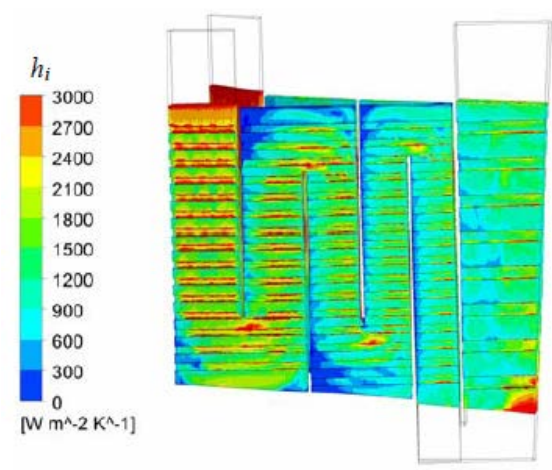

b) HTC contours at the inner surface

Fig. 8 The coolant flow and heat transfer of circuit 2

Fig. 9 shows the coolant flow, total pressure distribution and HTC distribution in circuit 3 . As the decrease of the cross area, the coolant flow accelerates along the coolant inflow loop, and local maximum velocity occurs at the near-hub region. Coolant flow accelerates to the trailing edge, and the heat transfer performance is augmented, so some of impingement effects occur at the trailing edge section. There are small vortices at the turning corner of the near-shroud region (see Fig. 9a), which result in poor heat transfer performance, and a low OCE region A occurs (see Fig, 6). The coolant flow has a notable total pressure loss at the turning corner, thus the mass flow rate in circuit 3 is relatively small. On account of the small mass flow rate and the high heat loading in the trailing edge portion, the cooling capability of the coolant consumes rapidly. At the location marked as $\mathrm{B}_{1}$ in Fig. 9, the coolant temperature is already about $1130 \mathrm{~K}$, thus low OCE exists in the region B (see Fig. 6). Although the high performance of V-shaped ribs are arranged in the coolant recovery loop, the downstream coolant has little cooling capability, the region C (see Fig. 6) both on suction side and pressure side suffers low OCE.

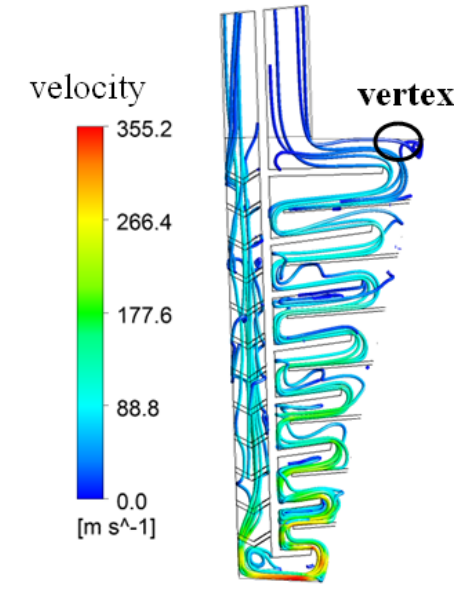

a) coolant flow

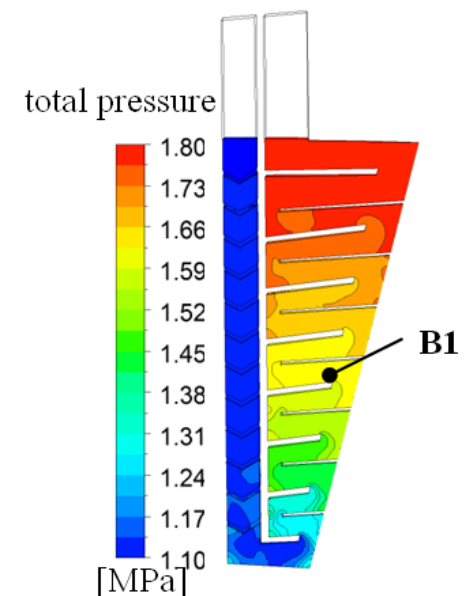

b) total pressure distribution

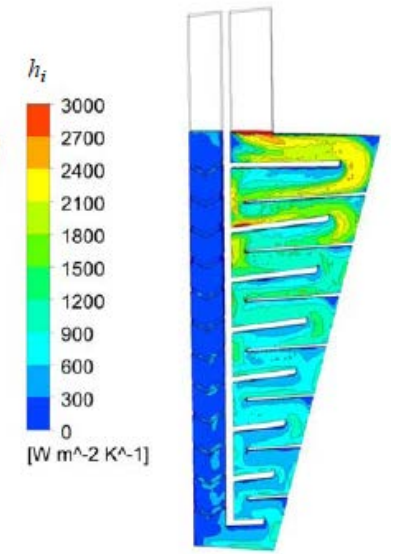

c) HTC distribution

Fig. 9 The coolant flow, total pressure distribution and HTC distribution in circuit 3

\section{Conclusion}

Numerical investigations on the closed-loop steam cooling configurations are carried out for an inlet guide vane. The cooling design has complex cooling configurations including impingement cooling at the leading edge region, serpentine passages at the mid-chord region and the impingement-tabulated baffles combined with $60^{\circ}$ inclined $\mathrm{V}$-shaped ribs at the trailing edge. The cooling performance of this cooling design is evaluated by using conjugate heat transfer method. Several low OCE regions are noticed, especially at most trailing edge portion based on the calculation result. Through the detailed flow and heat transfer analysis of all coolant circuits, the reasons why some low OCE regions exist are found out. 


\section{References}

[1] J. C. Han, S. Dutta, and S. Ekkad, Gas Turbine Heat Transfer and Cooling Technology, Taylor \& Francis Books, Inc (2000).

[2] D. Bohn, A. Wolff, M. Wolff, and K. Kusterer, Experimental and Numerically Invsetigation of a Steam-Cooled Vane, ASME Paper No. GT2002-30210 (2002).

[3] R. K. Matta, G. D. Mercer, and R. S. Tuthill, Power Systems for the 21st Century-'H' Gas Turbine Combined-Cycles, GER-3935 (1995).

[4] H. Nomoto, A. Konga, and S. Ito, The Advanced Cooling Technology for the $1500{ }^{\circ} \mathrm{C}$ Class Gas Turbine: Steam-Cooled Vanes and Air-Cooled Blades, Journal of Gas Turbines and Power, 1997, 119: 624-632.

[5] S.Ito, H. Saeki, E. Koda, T, Takahashi, M. Koyama, and T. Ninomiya, Conceptual Design and Cooling Blade Development of 1700 -Class High-Temperature Gas Turbine, ASME Paper No. GT2003-38352 (2003).

[6] E.Ito, K. Tsukagoshi, A. Muyama, J. Masada, and T. Torigoe, Development of the key technology for ultra-high-temperature gas turbines, Mitsubishi Heavy Industries Technical Review, 2010, 41(1): 19-25.

[7] J. Hu, Investigation on Closed-Loop Steam Cooling Schemes of a Gas Turbine Guide Vane, Master Thesis, Institute of Engineering Thermophysis, Chinese Academy of Sciences (2008).

[8] Z. Mazue, A. Hernández-Rossette, R. García-Illescas, and A. Luna-Ramírez, Analysis of Conjugate Heat Transfer of a Gas Turbine First Stage Nozzle, ASME Paper No. GT2005-68004 (2005).

[9] C. Zhang, J. J. Liu, Z. Wang, and B. T. An, Influence of Thermal Boundary Conditions in Conventional Heat Transfer Analysis of an Air-cooled Turbine Vane, Journal of Thermophysics, 2012, 33(5): 761-764.

[10]J. J. Liu, P. Li, C. Zhang, and B. T. An, Flowfield and Heat Transfer Past an Unshrouded Gas Turbine Blade Tip with Different Shapes, Journal of Thermal Science, 2013, 22(2): 128-134.

[11]B. T. An, J. J. Liu, and H. D. Jiang, Three-Dimensional Flow Analysis and Design Improvement of Leading-Edge Film-Cooling in an Inlet Guide Vane, ASME Paper No. GT2006-90234 (2006). 